\title{
Ações para a (trans)formação de professores
}

\section{Actions for (trans)formation of teachers}

\section{Claudia Lopes Pontara ${ }^{1}$; Ana Valéria Bisetto Bork ${ }^{2}$}

TELlES, J. A. (Org.). Formação Inicial $e$ continuada de professores de línguas: concepções e ações na pesquisa e na prática. Campinas: Pontes, 2009. 204p.

João A. Telles, docente da Universidade Estadual Paulista (UNESP), organizou o livro Formação Inicial e Continuada de Professores de Linguas: dimensões e ações na pesquisa e na prática, publicado pela Editora Pontes (2009). A obra apresenta dez trabalhos de professores pesquisadores que fazem parte do subgrupo de Formação do Professor, do Grupo de Trabalho de Linguística Aplicada da Associação Nacional de Pesquisa e Pós-Graduação em Letras e Linguística (ANPOLL).

O livro possui 204 páginas e está dividido em quatro eixos principais: a primeira parte refere-se ao desenvolvimento continuado de professores mediado por recursos tecnológicos (capítulos $1 \mathrm{e}$ 2); o segundo eixo está relacionado à linguagem e ao desenvolvimento continuado de professores (capítulos 3 e 4); o terceiro momento diz respeito ao desenvolvimento de professores, às políticas públicas e à questão da ação social (capítulos 5, 6, $7 \mathrm{e}$ 8); por último, o quarto eixo faz alusão à identidade, à reflexão e apresenta histórias profissionais de professores (capítulos 9 e 10).
No prefácio, a professora pesquisadora Maria Antonieta Alba Celani (PUC-SP) apresenta discussões extremamente significativas aos estudos na área de formação de professores. As suas contribuições chamam a atenção para o fato de que as lacunas na formação do professor passam não somente pelas questões pedagógicas, como também pelas especificidades do conteúdo que se tem como específico da disciplina. As colocações de Celani nos propiciam iniciar a leitura dos capítulos com um olhar crítico-reflexivo acerca das questões que envolvem a formação do professor de línguas.

No primeiro capítulo, Formação continuada online para professores de inglês: uma experiência de integração entre docência, pesquisa e extensão, Collins (PUC-SP) relata os resultados de uma experiência que integra extensão, pesquisa e docência online, a qual se deu por meio da oferta do curso “Teachers' Links: reflexão e desenvolvimento para professores de inglês, destinado a docentes de todos os segmentos. O curso tem como escopo três áreas teóricas: a concepção de design do curso, o conceito de mediação semiótica (focalizando os aspectos cognitivos, afetivos, sociais e culturais no processo de aprendizagem) e a relação entre a interação (sincrônica e assíncrona) e, por fim, a reflexão crítica. Como resultados, o texto nos propicia analisar alguns avanços elencados pela

\footnotetext{
${ }^{1}$ Professora de Língua Inglesa da Educação Básica do Estado do Paraná. Mestranda em Estudos da Linguagem - UEL.

${ }^{2}$ Professora de Língua Inglesa do Departamento Acadêmico de Línguas Estrangeiras Modernas (DALEM) da Universidade Tecnológica Federal do Paraná (UTFPR) - Câmpus Curitiba. Doutoranda em Estudos da Linguagem - UEL..
} 
autora no que diz respeito aos pesquisadores participantes na organização do curso (sejam eles pesquisadores em formação ou seniores).

No segundo capítulo, Ramos e Freire (PUCSP) apresentam o desenho, a implementação, o desenvolvimento e os resultados do projeto intitulado ESPTEC: formação de professores e multiplicadores de ensino-aprendizagem de inglês instrumental para o sistema de educação profissional de nível técnico. O projeto buscou suprir a carência de docentes com formação adequada na área, desenvolvendo um trabalho de formação de professores na e para a Abordagem Instrumental, englobando instituições federais e estaduais de nível técnico, responsáveis pela capacitação de seus próprios docentes e dos docentes de língua inglesa de suas respectivas regiões. O curso teve como eixo teórico a abordagem instrumental para o ensino de línguas, a formação crítico-reflexiva e a formação tecnológica do professor, com o desenvolvimento do letramento digital. Como resultados de pesquisa, as autoras trazem algumas percepções das professoras multiplicadoras, o que lhes permitiu elencar considerações a respeito do desenvolvimento teórico, bem como prático dos referidos professores.

No capítulo 3, Formação de professores pesquisadores: Argumentando e compartilhando significados, Liberali e Magalhães apresentam um estudo com base em dados coletados em dois projetos de extensão: Leitura nas diferentes áreas - LDA (2005, 2006) e Aprender Brincando AB (2007), os quais integram o Programa Ação Cidadã - PAC, vinculado a PUC-SP. Abordando conceitos de colaboração e argumentação, as autoras descrevem e discutem "os modos como a linguagem pode possibilitar questionamentos de sentidos em contextos de formação e a produção de conhecimentos em uma Cadeia Criativa". A partir das discussões teóricas e das análises realizadas por meio dos dois projetos já mencionados, as pesquisadoras trazem "uma investigação dos modos como a argumentação organiza o processo de produção de significados para que sentidos possam ser colaborativamente compartilhados." (LIBERALI; MAGALHÃES, 2009, p. 44).

No quarto capítulo, Pesquisas em linguagem: o que elas revelam sobre um projeto de educação continuada, Dutra e Melo (UFMG) apresentam os resultados do projeto Educação Continuada de Professores de Línguas Estrangeiras (EDUCONLE), cujo foco é o estudo da linguagem compreendida com mediadora da reflexão e instrumento de trabalho. Os resultados do estudo apontam para uma melhoria na competência linguística dos professores-alunos, o desenvolvimento da autoestima e da segurança e a sensação dos participantes de pertencer a um grupo que os auxilia no dia-a-dia profissional.

Formação prescrita e formação irrealizável de professores de línguas: alguns dilemas de uma escola inclusiva, apresentado no capítulo 5, é produzido por Lessa e Fidalgo, ambas vinculadas a PUC-SP. As autoras apresentam uma discussão acerca das possibilidades/dificuldades que envolvem o fazer docente tendo em vista a multiplicidade de diversidades que compõem a escola. Ao analisarem alguns documentos oficiais e relatos de professores, as autoras trazem à tona as falácias constantes em tais documentos, bem como a dura realidade enfrentada por educadores que vivenciam essas especificidades sem terem condições teórico-práticas para lidar com elas.

No capítulo 6, Ferreira (UNIOESTE) apresenta o texto Diversidade étnico-racial: histórias de professores de línguas. Partindo da apresentação de políticas públicas que tratam da diversidade étnico-racial, Ferreira inicia as discussões que nos levam a perceber claramente a necessidade de uma formação docente (seja ela inicial ou continuada) voltada para a temática em questão. Na sequência, a autora apresenta alguns relatos de professores participantes dos cursos de extensão "Formação de Professores de Línguas e Diversidade ÉtnicoRacial" e "Formação de Professores e Diversidade Étnico-Racial” (UNIOESTE - Cascavel, 2005), os 
quais exemplificam os benefícios percebidos pelos participantes.

No sétimo capítulo, Prado Gimenez e Mateus (UEL) apresentam o texto Rompendo barreiras em um projeto de aprendizagem sem fronteiras. Pautadas por uma perspectiva sócio-históricocultural, as autoras fazem uma breve retrospectiva acerca dos processos de formação de professores desde a década de 60 até os dias atuais, dando-nos um panorama sobre tais transformações de modo a podermos compreender o momento sócio-histórico que vivenciamos. As pesquisadoras apresentam os resultados obtidos a partir da realização do projeto "Aprendizagem sem Fronteiras" (20062007), o qual envolveu professoras formadoras da UEL, professoras da Educação Básica, professores novatos do Curso de Letras (UEL), alunos bolsistas de Iniciação Científica - IC Júnior do último ano do Ensino Médio e professoras pesquisadoras. O projeto diferencia-se pela experiência de trabalho colaborativo que propiciou a vivência do quadro teórico apresentado pela perspectiva sóciohistórico-cultural.

Gimenez (UEL), no capítulo 8, apresenta o texto Por uma tipologia de projetos de formação continuada de professores de Inglês, em que, partindo de iniciativas de formação continuada desenvolvidas em alguns estados brasileiros, a pesquisadora ancorada nos quesitos ações, emergência e objetivos dos projetos, referenciais teóricos, disseminação e impacto, planos futuros e sustentabilidade, analisa tais iniciativas para que se possa pensar na criação de "uma matriz de dimensões que caracterizariam projetos de formação continuada de professores de inglês" (GIMENEZ, 2009, p. 139). Ao final do estudo, Gimenez apresenta um quadro com as dimensões e opções visualizadas em sua investigação, o qual pode ser tomado como referência ao se pensar na oferta de atividades voltadas para a formação continuada de professores de línguas.

O capítulo 9 introduz o último eixo formador da coletânea com o texto intitulado Projeto aprendendo e ensinando línguas: construindo a relação com a teoria na prática de futuros professores de línguas. Nele, Castro (UNITAU) compartilha os resultados obtidos com o projeto realizado em 2007 e que recebeu o mesmo nome dado ao texto em questão, o qual contou com a participação de três alunas bolsistas da graduação, juntamente com dezesseis estagiárias voluntárias, sendo uma do Mestrado em Linguística Aplicada. Partindo, dentre outros, da teoria que embasa o trabalho de comunidade de prática de natureza colaborativa, na construção conjunta do conhecimento, nos princípios e procedimentos da pesquisa-ação, Castro apresenta as ações realizadas quando da execução do projeto. Os resultados alcançados evidenciaram o início da construção de um caminho que propiciou a seus participantes se firmarem "como protagonistas de sua formação profissional” (CASTRO, 2009, p. 164).

Completando o repertório de textos publicados no livro, Szundy (UFRJ) descreve o estudo intitulado Construção do conhecimento sobre a futura prática pedagógica: reflexões de alunos-professores sobre um projeto de prática de ensino da língua inglesa. $\mathrm{O}$ projeto, que recebe o mesmo título dado ao capítulo 10 , vem como uma alternativa para transformar a disciplina de Prática de Ensino de Língua Inglesa, pautada exclusivamente na observação de aulas, para a construção de um espaço privilegiado de reflexão e desenvolvimento de projetos pedagógicos. Embasada nos construtos teóricos que compõem os documentos oficiais (PCN, OCEM) e em Schneuwly e Dolz, Szundy aborda questões relativas ao ensino de e por meio de gêneros, as capacidades de linguagem, a transposição didática e a sequência didática. A autora apresenta algumas análises dos relatórios escritos pelas participantes do projeto que cursaram a disciplina de Prática de Ensino.

Os dez trabalhos acima descritos puderam, num conjunto, suscitar discussões acerca de uma grande parte da problemática que envolve a formação do professor, seja essa formação inicial ou continuada. 
Foi possível aliar a teoria à prática, uma vez que os autores trouxeram a preocupação com uma formação de professores que não se restringisse somente ao embasamento teórico, mas principalmente, que permitisse a realização de projetos/ações em que a práxis fosse evidenciada, na busca de uma formação que se fizesse autônoma, crítica, colaborativa, reflexiva.

\section{Referências}

CASTRO, S. T. R. O projeto aprendendo e ensinando línguas: construindo a relação com a teoria na prática de futuros professores de línguas. In: TELLES, J. A. (Org.). Formação inicial $e$ continuada de professores de línguas: concepções e ações na pesquisa e na prática. Campinas: Pontes, 2009.

GIMENEZ, T. Por uma tipologia de projetos de formação continuada de professores de inglês. In: TELLES, J. A. (Org.). Formação inicial $e$ continuada de professores de línguas: concepções e ações na pesquisa e na prática. Campinas: Pontes, 2009.

LIBERALI, F. C.; MAGALHÃS, M. C. C. Formação de professores e pesquisadores: argumentando e compartilhando significados. In: TELLES, J. A. (Org.). Formação inicial e continuada de professores de línguas: concepções e ações na pesquisa e na prática. Campinas: Pontes, 2009. 